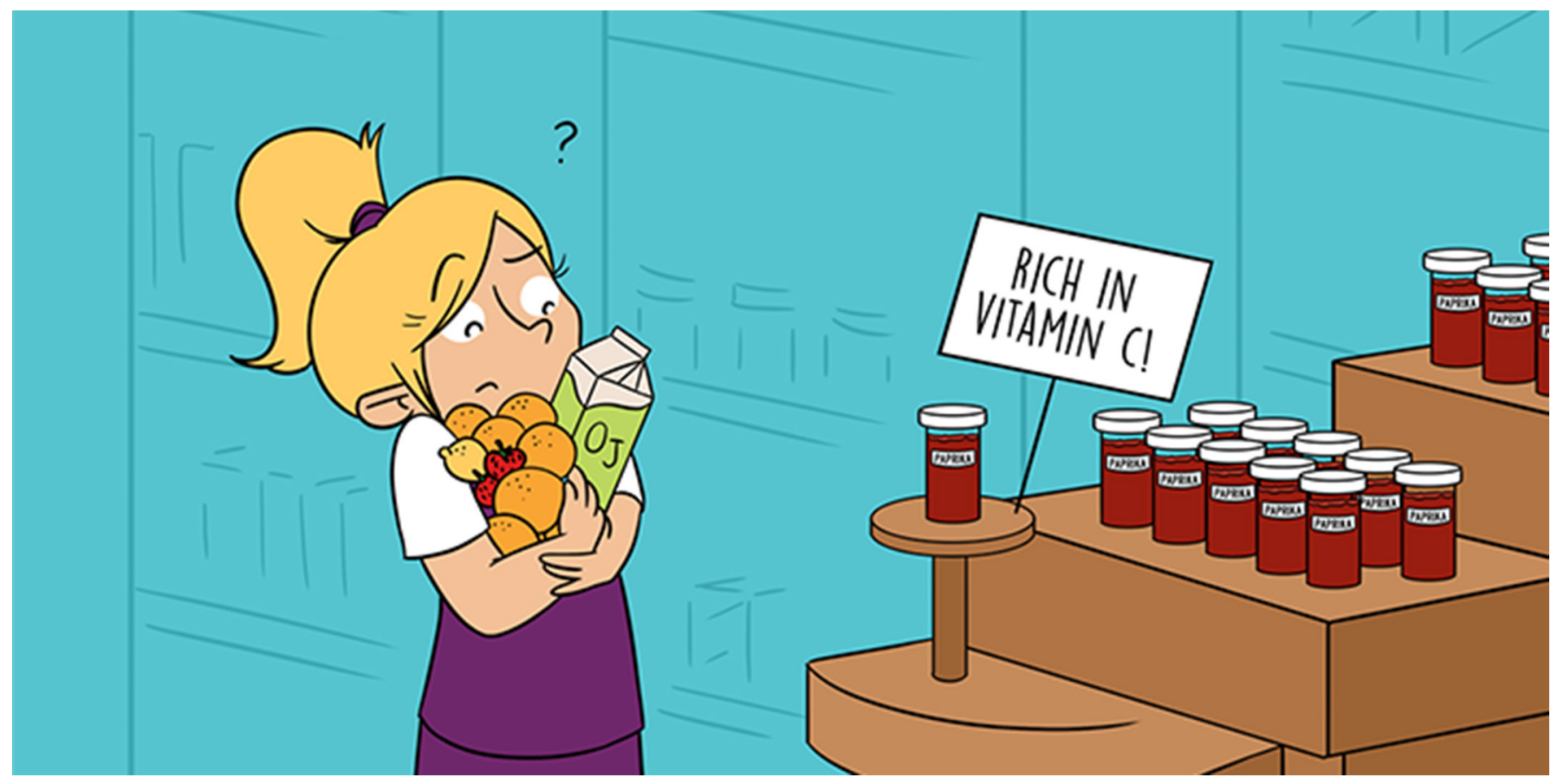

\title{
ALBERT SZENT-GYÖRGYI-THE SCIENTIST WHO DISCOVERED VITAMIN C
}

\section{Hana Shiref and Michelle A. Sahai *}

Department of Life Sciences, University of Roehampton, London, United Kingdom

YOUNG REVIEWERS:



ALESSIO

AGE: 15

ANTONIO

AGE: 14

DAVIDE

AGE: 15

GIOVANNI

AGE: 14
In the 1920s and 1930s, Dr. Albert Szent-Györgyi, a Hungarian professor of medicinal chemistry, made some very important discoveries that help us to understand basic nutrition. While conducting a series of early experiments on citrus plants, he found that plant browning could be caused by peroxidase, a plant enzyme that is active during oxidation. By adding citrus juice to peroxidase, the browning process could be stopped. In his experiments he isolated a substance he called, hexuronic acid that he thought was active within citrus juice. This was one of the first steps in the discovery of what we know today as vitamin C. Szent-Györgyi, also conducted experiments on guinea pigs, which are similar to humans, in that they have to consume hexuronic acid to remain healthy. He decided to rename hexuronic acid to ascorbic acid or vitamin C, reflecting its anti-scorbutic (scurvy fighting) properties. It took many years to find a way to produce large amounts of ascorbic acid from natural sources. It was by chance he found the answer in his dinner! The story goes that he did not want to eat the paprika in his dinner, so he took it to his laboratory, where he found it to contain large 


\section{VITAMIN C}

A water-soluble vitamin important for healthy skin, teeth, bones, and blood vessels. It is found especially in citrus fruits, tomatoes, potatoes, and green leafy vegetables. Also called ascorbic acid.

\section{SCURVY}

A disease caused by a lack of vitamin C, characterized by anaemia, spongy gums, bleeding beneath the skin, and (in infants) malformation of bones and teeth.

\section{VITAMIN}

Vitamins are a group of organic micronutrients that are required by the body for healthy growth, development and immune system functioning.

\section{HEXURONIC ACID}

Any uronic acid derived from a hexose. Was also known as Ascorbic acid (vitamin C).

\section{ASCORBIC ACID}

See Vitamin C. amounts of vitamin C. Without his discovery we would not know that vitamin $C$ is important for proper functioning of our immune system. By eating our daily dose of fruits and vegetables, which contain vitamin $C$, we improve the repair and growth of tissue and many more factors that keep us healthy. Szent-Györgyi was awarded the Nobel Prize in Physiology or Medicine in 1937 for his discovery of vitamin C. He is also known for his later contribution to what we know as the Citric Acid (Krebs) cycle.

\section{“Discovery consists of seeing what everybody has seen and thinking what nobody has thought."}

\section{-Albert Szent-Györgyi in Irving Good, The Scientist Speculates (1962).}

Vitamin C's discovery begins with a disease called scurvy. Prolonged vitamin $C$ deficiency leads to scurvy and, if left untreated, can be fatal. Symptoms of scurvy include feeling tired, bleeding gums or skin that bruises. As these symptoms worsen, patients may develop open sores, lose teeth and can even die. Other symptoms include impaired wound healing, muscle weakness and hemorrhages (an escape of blood from a ruptured blood vessel). Sounds pretty nasty, right? People have complained about this disease since ancient times. Some records of scurvy have been around since 1500 BC Egypt [1]. Scurvy was a big problem for sailors in the eighteenth century. They ate a lot of dried meats and grains and did not include fruits and vegetables in their diet. This was because these foods would not remain fresh on long sea journeys. In 1757, James Lind, a Scottish doctor, discovered that fresh citrus fruits could prevent scurvy. It was then mandatory for sailors in the British navy to consume citrus fruits and lemon juice [2].

In 1907, other scientists like Axel Holst and Alfred Frohlich proposed that a special substance existed in these fruits [2] while Casimir Funk coined the term Vitamin C in 1912 [3]. He developed the concept of vitamins, and showed that these "vital" substances were needed to keep people healthy and free of disease. His terminology as well as the discovery made by Holst and Frohlich led to the substance being called "water-soluble C" which then eventually became Vitamin C. Only in 1928 did the scientist Albert Szent-Györgyi identify this unique substance, which he referred to as hexuronic acid [2].

\section{WHAT IS VITAMIN C?}

Ascorbic acid (vitamin C) is an organic compound made of carbon, hydrogen, and oxygen (Figure 1). It is a white solid, made synthetically from sugar dextrose when it is in its purest form. It can also be used as a vitamin supplement or as a food preservative [4]. 


\section{Figure 1}

Ascorbic acid or Vitamin C. The (A)

2-dimensional structural formula and (B) 3-dimensional structure of ascorbic acid. The black, red, and white colors represent the atomic elements carbon, oxygen, and hydrogen, respectively.

\section{MULTIVITAMIN}

A pill or tablet containing several vitamins.

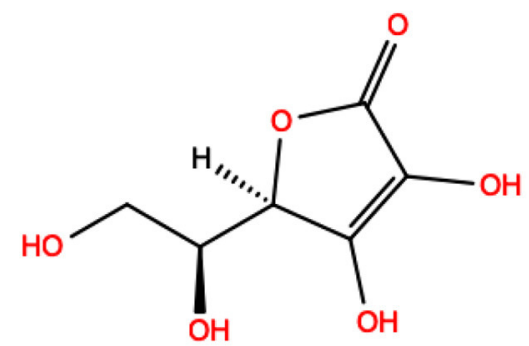

(A)

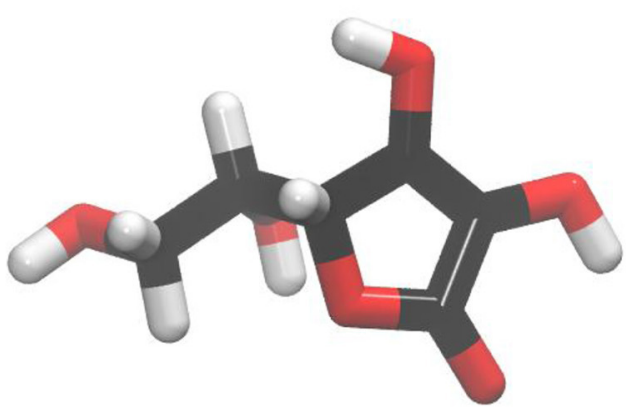

(B)

Figure 1

\section{WHY IS VITAMIN C SO IMPORTANT?}

Have your parents told you to drink orange juice when you were sick? This is because orange juice has a high level of vitamin $C$ and can keep us healthy or treat a cold. The human body is unable to produce vitamin $\mathrm{C}$ and we must therefore get it through our food or by taking a multivitamin.

Vitamin $C$ allows the body to use carbohydrates, fats, and protein. It acts as an antioxidant, meaning it can chemically bind and neutralize the tissue damaging effects of substances called free radicals. It is important for the growth and health of bones, teeth, blood vessels, gums, and ligaments. It is also involved in the forming of collagen, the main structural protein within the body. Collagen is vital for the proper functioning of internal organs [4].

\section{FOOD SOURCES WITH VITAMIN C}

Did you know that many fruits and vegetables can provide you with the correct amount of vitamin C? They include foods like oranges, lemons, spinach, kiwifruit, strawberries, limes, tomatoes, grapefruit, Brussels sprouts, red and green peppers, cabbage, potatoes, and broccoli. Cooking your food can destroy vitamin C, so it is good news that there are many food sources of vitamin C to keep you healthy! [4].

\section{EARLY LIFE AND THE DISCOVERY OF HEXURONIC ACID}

Albert Szent-Györgyi was born on 16 September 1893 in Budapest, Hungary. His family had produced three generations of scientists [2]. As a result, he developed an interest in science from an early age. He studied medicine at the University of Budapest and also worked in his uncle's laboratory before World War I. He served in the military during the war and in 1917 had to leave the military after being injured. He also received a Silver Medal of Military Valor for his service. After receiving his medical degree, he went on to study at different European universities [2]. 
His scientific career began with studying the chemical changes that happen when cells in our body use proteins, fats, and carbohydrates. This process is called cellular respiration. He studied this process by isolating a molecule in the adrenal glands, which are small glands located on top of each kidney that produce a variety of hormones. This molecule is able to lose and regain hydrogen atoms and contains six carbon atoms. It also contains properties of both sugar and an acid. Albert Szent-Györgyi named it hexuronic acid because of these properties.

In the 1920's, Szent-Györgyi's interest turned to cellular respiration and energy production in plants. He started to investigate the browning processes that interrupt growth and normal functioning. He found that plants begin to brown because of cellular damage. This damage affects the mechanism that supplies hydrogen, which stops oxidation-a process in which one atom strips electrons from another, claiming them as its own. He found that browning could be caused by peroxidase, a plant enzyme that is active during oxidation. By adding citrus juice to peroxidase, the browning process could be stopped. In his experiments he isolated the hexuronic acid substance that he thought was active within citrus juice.

He started to work with a chemist named J. L. Svirbely. Svirbely and Szent-Györgyi conducted experiments on guinea pigs. Guinea pigs are similar to humans, because they have to consume vitamin $\mathrm{C}$ to remain healthy. This is because it cannot be made within their bodies.

In this experiment, the animals were divided into two groups. One group of guinea pigs received boiled food, where the boiling process destroyed vitamin $\mathrm{C}$. The other group was fed food that was enriched with hexuronic acid. The second group thrived and remained healthy, whilst the first group developed scurvy-like symptoms and later died. Szent-Györgyi and Svirbely decided to rename hexuronic acid to ascorbic acid, reflecting its anti-scorbutic (scurvy fighting) properties [4]. By 1933, Szent-Györgyi had used all of the hexuronic acid he isolated from the adrenal glands of the guinea pigs. He then had to find natural sources of vitamin $\mathrm{C}$ to complete his study.

\section{VITAMIN C IN PAPRIKA!}

Orange juice and lemon juice contain high levels of ascorbic acid. They also contain many sugars which makes it difficult to obtain a pure sample. Szent-Györgyi therefore thought of a surprising solution-using paprika. Paprika is native to Szeged, Hungary. Szent-Györgyi wrote in his autobiography that one night after his wife served fresh red paprika for dinner: "I did not feel like eating it, so I thought of a way out. Suddenly it occurred to me that this is the one plant I had never tested. I took it to the laboratory... [and by] about midnight I knew that it was a treasure chest full of vitamin C." In his 


\section{CITRIC ACID CYCLE}

Also known as the Krebs Cycle; a metabolic pathway found in aerobic organisms that oxidizes acetyl coA groups to carbon dioxide and water, producing 1 ATP and a number of coenzymes that play a vital role in the next step of respiration oxidative phosphorylation laboratory he used paprika to produce 3 lbs of pure crystalline ascorbic acid. This was enough to give to the vitamin $\mathrm{C}$-deficient guinea pigs and he determined that this acid was equivalent to vitamin C [5].

\section{NOBLE PRIZE WINNING WORK: THE CITRIC ACID (KREBS) CYCLE}

Do you remember Albert Szent-Györgyi's earlier work on plant respiration? He studied cellular respiration processes within muscle cells and conducted experiments on the pectoral muscles of pigeons. He looked at the processes in this biochemical cycle that produce energy in the form of adenosine triphosphate (ATP) from proteins, carbohydrates, and fats. ATP is known to be the source of energy within cells. He noticed that ATP had a very important role. He also identified the role of fumaric acid in this process. In 1937, Szent-Györgyi was awarded the Nobel Prize in Physiology or Medicine to for these discoveries.

Another scientist, Hans Krebs, found that citrate (or citric acid in its protonated form), the first molecule to form during the cycle's reactions, was very important. This cycle is known as the Citric Acid (Krebs) Cycle, referring to both Szent-Györgyi's and Krebs' work (Figure 2). It is also called the tricarboxylic acid cycle due to the three-carboxyl groups found on its first two intermediates.

This cycle contains eight steps that take place within the matrix of the mitochondria of the cell and is central to cellular respiration. The four-carbon molecule, oxaloacetate, which begins the cycle is regenerated after the eight steps (Figure 2). These steps are a series of redox, dehydration, hydration, and decarboxylation reactions. One turn of the cycle releases two carbon dioxide molecules and produces three NADH, one FADH2, and one ATP/GTP. These molecules will then be utilized in further steps of cellular respiration, producing ATP for the cell [6].

\section{LATER WORK AND LEGACY}

In 1947, after receiving the Nobel prize, Albert Szent-Györgyi immigrated to the United States. He worked at the Institute for Muscle Research in Woods Hole, Massachusetts. He continued to research and investigate the causes of cell division and cancer. Albert Szent-Györgyi died on 22 October 1986. No doubt we owe much to this great scientist, whose landmark discoveries laid the foundation for proper nutrition. 
Figure 2

Overview of the citric acid (Krebs) cycle that consists of eight steps. Created with BioRender.com.



\section{REFERENCES}

1. Agarwal, A., Shaharyar, A., Kumar, A., Bhat, M. S., and Mishra, M. 2015. Scurvy in pediatric age group-a disease often forgotten? J. Clin. Orthop. Trauma 6:101-7. doi: 10.1016/j.jcot.2014.12.003

2. Baron, J. H. 2009. Sailors' scurvy before and after James Lind-a reassessment. Nutr. Rev. 67:315-32. doi: 10.1111/j.1753-4887.2009.00205.x

3. Piro, A., Tagarell, A., and Quattrone, A. 2019. The discovery of beri-beri and scurvy vitamins - two hundred and two years from its discovery. Int. J. Vitam. Nutr. Res. 89:225-6. doi: 10.1024/0300-9831/a000435

4. Lykkesfeldt, J., Michels, A. J., and Frei, B. 2014. Vitamin C. Adv. Nutr. 5:16. doi: 10.3945/AN.113.005157

5. Svirbely, J. L., and Szent-Györgyi, A. 1933. The chemical nature of vitamin C. Biochem. J. 27:279-85.

6. Kelly, D. J., and Hughes, N. J. 2001. The Citric Acid Cycle and Fatty Acid Biosynthesis. Available online at: http://www.ncbi.nlm.nih.gov/pubmed/ 21290715 (accessed August 31, 2019).

SUBMITTED: 01 September 2019; ACCEPTED: 06 February 2020; PUBLISHED ONLINE: 03 March 2020.

EDITED BY: Pasquale Maffia, University of Glasgow, United Kingdom 

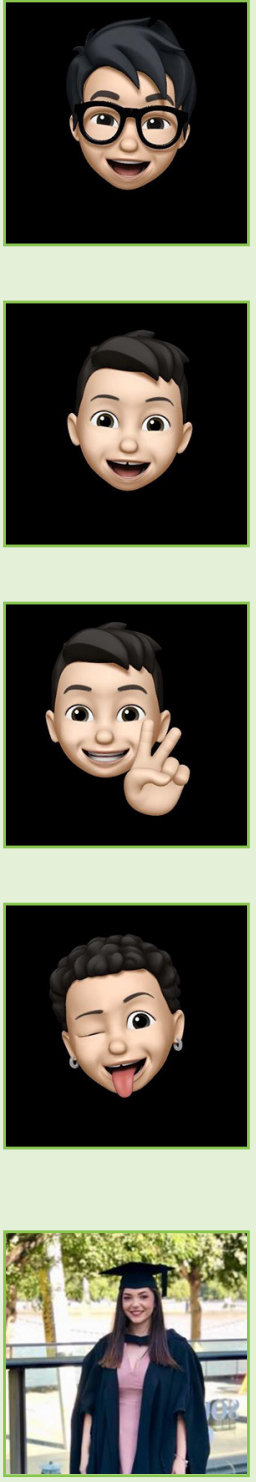

CITATION: Shiref H and Sahai MA (2020) Albert Szent-Györgyi-The Scientist Who Discovered Vitamin C. Front. Young Minds 8:19. doi: 10.3389/frym.2020.00019

CONFLICT OF INTEREST: The authors declare that the research was conducted in the absence of any commercial or financial relationships that could be construed as a potential conflict of interest.

COPYRIGHT () 2020 Shiref and Sahai. This is an open-access article distributed under the terms of the Creative Commons Attribution License (CC BY). The use, distribution or reproduction in other forums is permitted, provided the original author(s) and the copyright owner(s) are credited and that the original publication in this journal is cited, in accordance with accepted academic practice. No use, distribution or reproduction is permitted which does not comply with these terms.

\section{YOUNG REVIEWERS}

\section{ALESSIO, AGE: 15}

I am a High School student. I live in Naples and I like playing videogames and watching anime. My favorite sport is football.

\section{ANTONIO, AGE: 14}

$\mathrm{Hi}$, my name is Antonio, I study electronic and I enjoy football and music.

\section{DAVIDE, AGE: 15}

$\mathrm{Hi}$, my name is Davide. I am a student in electronic from Naples, I like all kind of sports and TV series and I really like foreign languages, especially English.

\section{GIOVANNI, AGE: 14}

My name is Giovanni, I am 14 years old and I attend a Neapolitan high school. I play guitar and I love metal.

\section{AUTHORS}

\section{HANA SHIREF}

I am a recent graduate from the University of Roehampton, where I studied Biomedical Science as my undergraduate degree and Clinical Neuroscience for my Master's degree. I am particularly interested in using computational methods as a means of investigating the dopamine transporter. I am passionate about science and hope to have a bright future within the field. Besides my studies, I enjoy socializing with friends and playing my guitar and keyboard. 


\section{MICHELLE A. SAHAI}

I am a Senior Lecturer at the University of Roehampton. I teach Molecular Biology and Biochemistry, as well as Bioinformatics and Computational chemistry at the undergraduate and graduate level. I make use of super computers to study large biological molecules, especially membrane proteins. I am particularly interested in the interactions of small molecules or illegal drugs with these proteins. Besides research and teaching, I enjoy spending time with my family, reading, and traveling. *michelle.sahai@roehampton.ac.uk 